ISAHP 2003, Bali, Indonesia, August 7-9, 2003

\title{
A FRAMEWORK FOR UNIVERSITIES-SELECTION DECISIONS USING THE ANALYTIC NETWORK PROCESS (ANP)
}

\author{
Kochoke Poonikom and Chuvej Chansa-ngavej \\ Department of Industrial Engineering, \\ Faculty of Engineering,Chulalongkorn University, Phayathai Rd., \\ Patumwan, Bangkok 10330, THAILAND \\ + enkochpo@ubu.ac.th \\ \# chuvej@1ycos.com \\ Christopher O'Brien
}

School of Mechanical, Materials, Manufacturing Engineering and Management,

The University of Nottingham,University Park,

Nottingham NG7 2RD, ENGLAND

Chris.Obrien@nottingham.ac.uk

Keywords: University Selection Problem, Multiple Criteria Decision Making, Engineering Discipline, Analytic Network Process (ANP)

\begin{abstract}
Choosing the right universities for first degree study is one of the most complex real-life problems for prospective students and their guardians. In addition, the outcome of the decision will affect not only the decision-makers but also their family, society and ultimately all sectors of the country. As such, selecting the universities is a critical decision that is just as important as business decision making. Therefore, prospective students need to have a framework to assist them in achieving their life-time goals. However, there are several tangible and intangible factors influencing the university selection problem. At the same time, the prospective students may need to achieve various objectives relying not only on academic reputation but also on other criteria such as the admission system and outcomes. Financial requirements, faculty and academic resources, curriculum, social experiences and so forth are major criteria to take into consideration in deciding which are the most suitable universities to apply for in the specific education program for the potential applicants. This paper proposes a framework in the selection of universities for prospective students using the Analytic Network Process (ANP) as the tool to examine these issues. The proposed model is applied to the engineering discipline in Thailand.
\end{abstract}


